\title{
Lessons learned for social and behavior change programming from the USAID Zika response
}

Martha Silva

Julia Fleckman

Jeni Stolow

Kendra LeSar

Kamden Hoffmann

See next page for additional authors

Follow this and additional works at: https://knowledgecommons.popcouncil.org/departments_sbsr-pgy How does access to this work benefit you? Let us know!

\section{Recommended Citation}

Silva, Martha, Julia Fleckman, Jeni Stolow, Kendra LeSar, Kamden Hoffmann, and Paul C. Hewett. 2020. "Lessons learned for SBC programming from the USAID Zika response," Breakthrough RESEARCH Technical Report. Washington, DC: Population Council. 


\section{Authors}

Martha Silva, Julia Fleckman, Jeni Stolow, Kendra LeSar, Kamden Hoffmann, and Paul C. Hewett 


\section{TECHNICAL REPORT}

\section{Lessons Learned for \\ SBC Programming from the USAID Zika Response}

FEBRUARY 2020

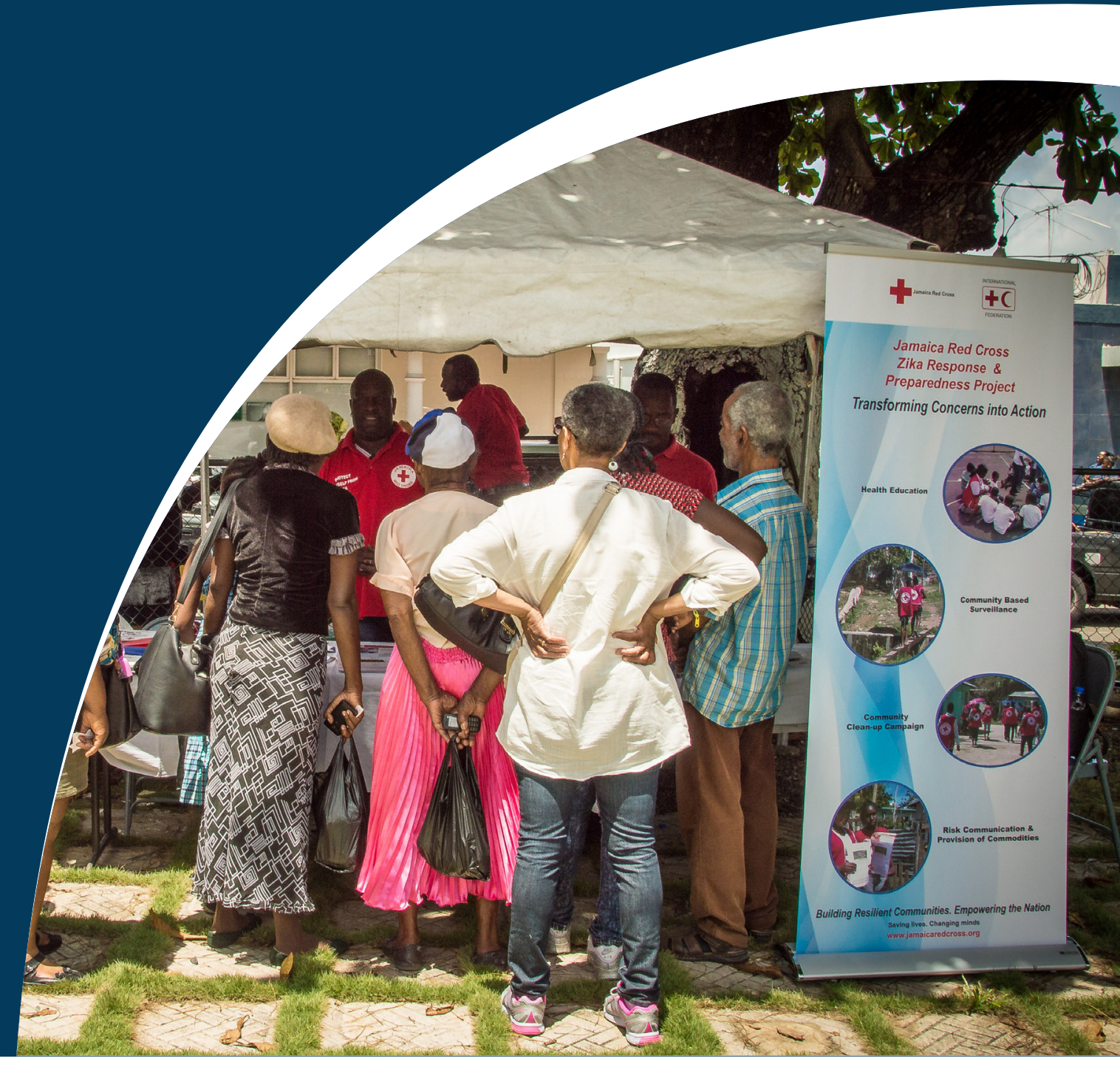

(E) USAID

(ํㅜㄴ) Tulane

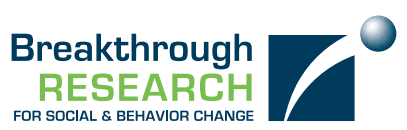




\section{Acknowledgments}

This technical report described work led by Tulane University under Breakthrough RESEARCH. Qualitative interviews described in Guatemala, El Salvador, Honduras, Dominican Republic, and Peru were conducted by independent consultants Maria Elena Guardado and Jose Manuel Aguilar. The authors would like to thank Dominique Meekers (Tulane University), Gabrielle Hunter and Priya Parikh (Johns Hopkins University Center for Communication Programs), and Arianna Serino (United States Agency for International Development) for their technical review and feedback, as well as the many Zika implementing partners who contributed documentation, interviews, and responses to follow-up questions throughout this process.

\section{USAID \\ FROM THE AMERICAN PEOPLE}

Breakthrough RESEARCH is made possible by the generous support of the American people through the United States Agency for International Development (USAID) under the terms of cooperative agreement no. AID-OAA-A-17-00018. The contents of this document are the sole responsibility of the Breakthrough RESEARCH and Population Council and do not necessarily reflect the views of USAID or the United States Government.

\section{Tulane I University}

As stewards of the first school of public health in the United States, the Tulane University School of Public Health and Tropical Medicine cultivates independent thinkers, innovative leaders, fierce advocates, and accomplished scholars.

From the neighborhoods of New Orleans to communities worldwide, we conduct research and collaborate with our partners to ensure that all of humanity has an equitable opportunity to be healthy and pursue optimal well-being.

We train the problem solvers. Find us on the Front Lines.

\section{POPULATION \\ COUNCIL}

Ideas. Evidence. Impact.

The Population Council confronts critical health and development issuesfrom stopping the spread of HIV to improving reproductive health and ensuring that young people lead full and productive lives. Through biomedical, social science and public health research in about 50 countries, the Council works with our partners to deliver solutions that lead to more effective policies, programs, and technologies to improve lives worldwide. Established in 1952 and headquartered in New York, the Council is a nongovernmental, nonprofit organization with an international board of trustees.

\section{Breakthrough
RESEARCH}

Breakthrough RESEARCH catalyzes social and behavior change (SBC) by conducting state-of-the-art research and evaluation and promoting evidence-based solutions to improve health and development programs around the world. Breakthrough RESEARCH is a consortium led by the Population Council in partnership with Avenir Health, ideas42, Institute for Reproductive Health at Georgetown University, Population Reference Bureau, and Tulane University.
(C)2020 The Population Council. All rights reserved.

Cover photo by (C2018 Stephen Kierniesky, Courtesy of Photoshare

\section{Suggested Citation}

Silva, Martha, Julia Fleckman, Jeni Stolow, Kendra LeSar, Kamden Hoffmann, and Paul C. Hewett. 2020. "Lessons learned for SBC programming from the USAID Zika response." Breakthrough RESEARCH. Washington DC: Population Council.

\section{Contact}

4301 Connecticut Avenue NW, Suite 280 | Washington, DC 20008

+1202 2379400 | BreakthroughResearch@popcouncil.org

breakthroughactionandresearch.org 


\section{Lessons Learned for SBC Programming from the USAID Zika Response}

Martha Silva

Kendra LeSar

Tulane University

Population Council
Julia Fleckman

Kamden Hoffmann
Jeni Stolow

Paul C. Hewett 


\section{List of Acronyms}

ASSIST

Applying Science to Strengthen and Improve Systems

CAZ

Community Action on Zika

CZS

Congenital Zika Syndrome

C4D

Communication for Development

$\mathrm{HC3}$

Health Communication Capacity Collaborative

$\mathrm{HCD}$

Human-centered Design

$\mathrm{HQ}$

Headquarters

IFRC

International Federation of the Red Cross

IP

Implementing Partner

IPC

Interpersonal Communication

KAP

Knowledge, Attitudes, and Practices

MERL

Monitoring, Evaluation, Research, and Learning

MCDI

Medical Care Development International

PAHO

Pan American Health Organization

PAR

Participatory Action Research

PASMO

Pan American Social Marketing Organization

PSI

Population Services International

SBC

Social and Behavior Change

UNICEF

United Nations International Children's Emergency Fund

USAID

United States Agency for International Development

USG

United States Government

WHO

World Health Organization

ZAP

Zika Airs Project 


\section{Table of Contents}

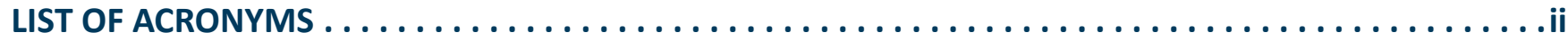

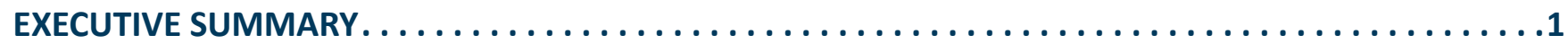

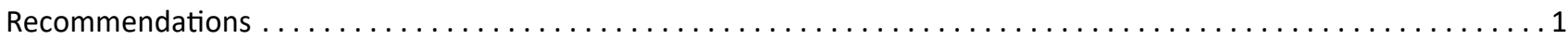

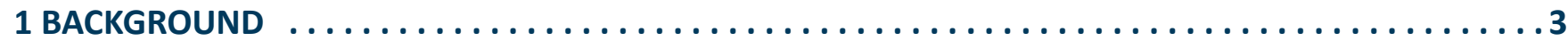

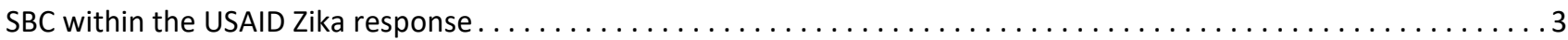

Extracting the lessons learned of SBC programming within the USAID Zika response $\ldots \ldots \ldots \ldots \ldots \ldots \ldots \ldots$

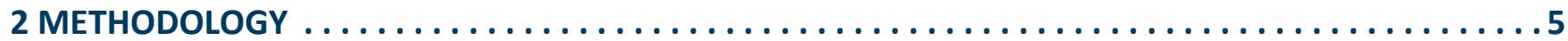

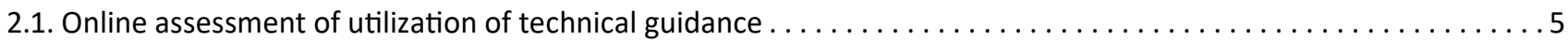

2.2. Systematic comparison of KAP data collection instruments and methods $\ldots \ldots \ldots \ldots \ldots \ldots \ldots \ldots \ldots \ldots$

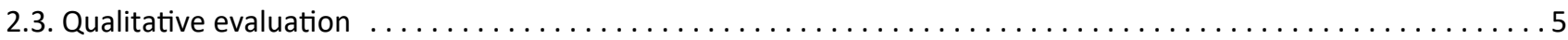

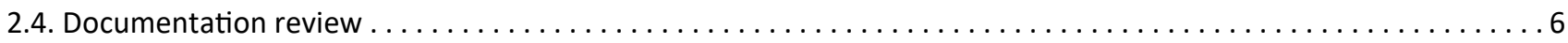

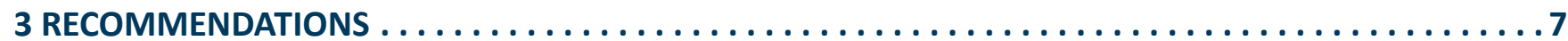

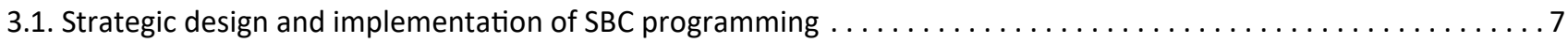

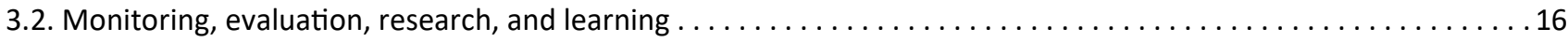

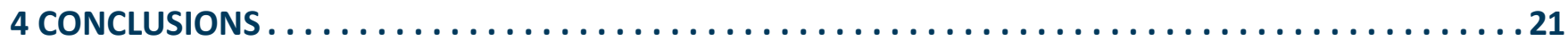

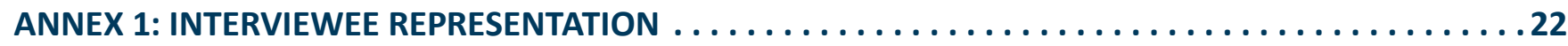

ANNEX 2: EXAMPLES OF RAPID DATA COLLECTION TECHNIQUES $\ldots \ldots \ldots \ldots \ldots \ldots \ldots \ldots \ldots \ldots$

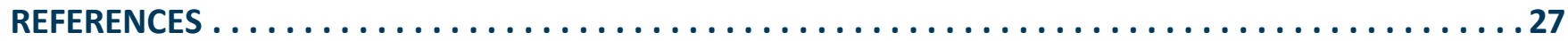




\section{EXECUTIVE SUMMARY}

Following the World Health Organization's (WHO) declaration of a public health emergency of international concern due to the Zika virus outbreak in 2015, the United States Agency for International Development (USAID) supported a regional Zika response. The USAID response was composed of four lines of effort: (1) social and behavior change (SBC) communication; (2) vector control; (3) service delivery; and, (4) research and innovation, and included gender integration and community engagement as crosscutting themes. As the outbreak abated and the USAID Zika response wound down, Breakthrough RESEARCH was tasked with documenting the strengths, weaknesses, gaps, and challenges experienced through the SBC line of effort to inform future public health emergency programming. The following questions guided this documentation:

1. What were the successes, challenges, and gaps in designing, implementing, and adapting SBC programming in the USAID Zika response?

2. What were the successes, challenges, and gaps in generating and using data and evidence in SBC programming in the USAID Zika response?

3. What do the successes, challenges, and gaps of the USAID Zika response's SBC programming imply for future health emergency responses?

These lessons learned data collection efforts were carried out in different phases from August 2018 to November 2019 and consisted of: (1) an online assessment of implementing partners' (IP) utilization of key SBC technical guidance documents; (2) a systematic comparison of quantitative knowledge, attitudes, and practices survey instruments and methods across settings;

(3) qualitative in-depth interviews with 77 stakeholders representing USAID (headquarters [HQ] and field offices), IPs (HQ and regional and country offices), and ministry of health representatives; and, (4) a review of documentation from IPs compiling their own lessons learned.

The following eight recommendations derived from this assessment are noted below and based on lessons learned from the design and implementation of SBC activities during the USAID Zika response:

\section{Recommendations}

1. A strong coordination for SBC in the emergency response is needed to ensure collaboration, harmonization, and joint SBC planning and implementation. Establishing a multi-tiered platform of working groups at $\mathrm{HQ}$, regional and country-level consisting of key stakeholders early in the emergency response furthers the alignment and harmonization of SBC planning and implementation. Where possible, existing structures should be leveraged for country-level coordination.

2. At the outset of a public health emergency response, determine priority behaviors through a participatory process with all stakeholders. This process may be more effective if facilitated by a partner with SBC technical expertise and include a review of the most robust evidence available as well as discussions of contextual considerations that may impede behavior change.

3. SBC should be recognized as a crosscutting line of work and integrated into other technical areas within public health emergency responses.

4. Develop solutions informed by participatory design methods, such as human-centered design (HCD), within the mix of SBC strategies, given their potential advantages for public health emergency responses. 
5. Given the constraints of emergency programming, ensure attention is given to identifying and mobilizing the appropriate SBC expertise within projects and consider including an IP that can provide SBC technical assistance to partners and governments should they need it.

6. Ensure that SBC activities are based on addressing contextually relevant determinants, facilitators, and barriers of behaviors that have been identified from rapid formative research conducted at the start of a response.
7. Agree upon indicator definitions and data sources among a specified list of SBC key indicators to allow for comparability across partners and countries; building in flexibility by using sub-indicators that are specific to IP programs or are needed for context-specific reasons.

8. Given the constraints of public health emergency responses, ensure coordination of research and evaluation activities from the beginning of the response.

(C)2018 Stephen Kierniesky, Courtesy of Photoshare

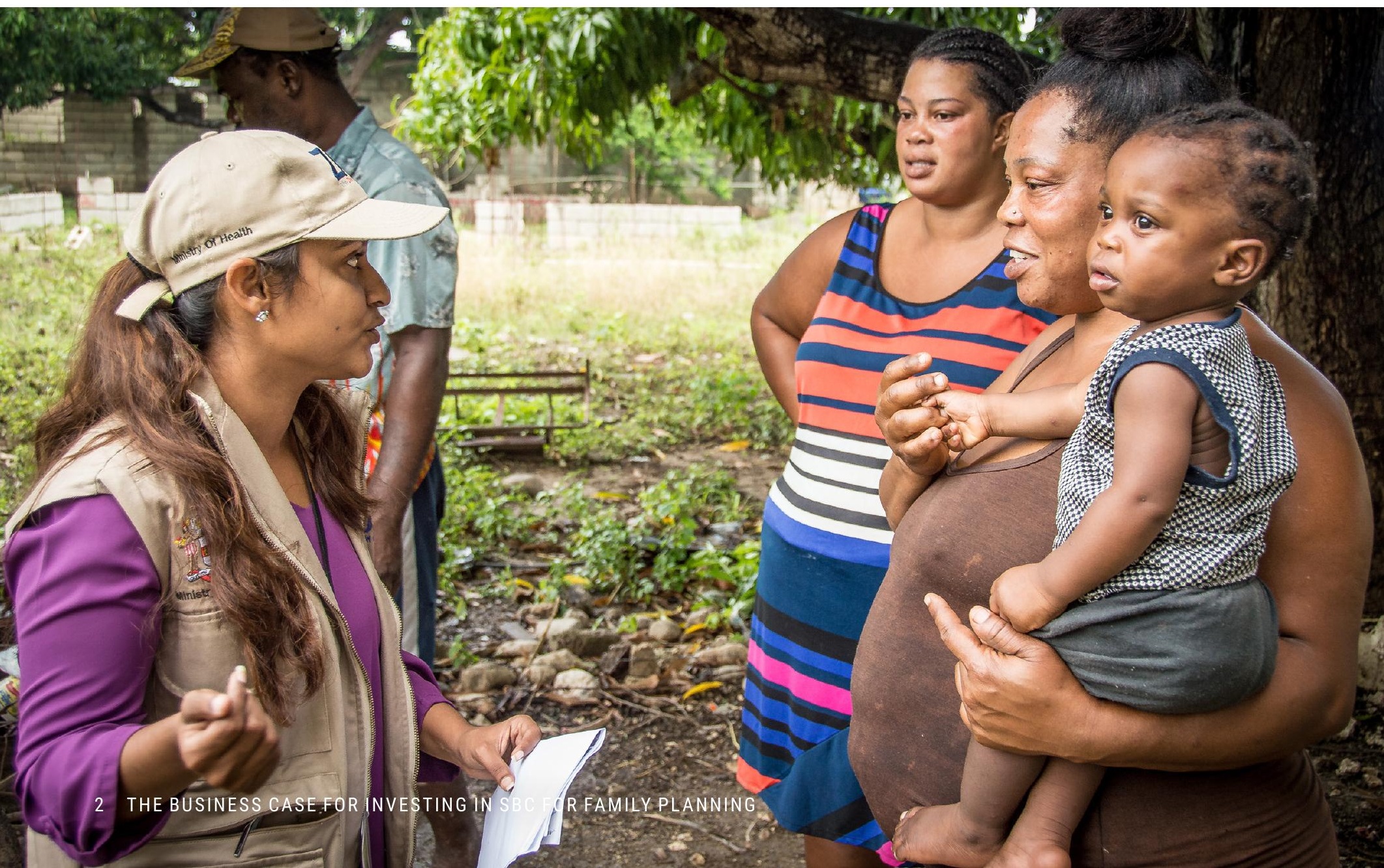




\section{BACKGROUND}

In response to the Zika virus epidemic in the Americas, in February 2016, WHO declared the spread of Zika a Public Health Emergency of International Concern. ${ }^{1,{ }^{*}}$ At the start of the epidemic, there were significant gaps in knowledge pertaining to the modes of transmission and health impact of the Zika virus. Today, it has been established that Zika is an arbovirus transmitted by Aedes aegypti mosquitoes, as are other diseases in the region, including dengue, chikungunya, and yellow fever. It has been also found that the Zika virus can be transmitted sexually, as well as vertically from mother to child. While some infected people present with mild symptoms, such as rash, fever, muscle and joint pain, malaise, headache, and conjunctivitis, between 29 and 82 percent of Zika cases are asymptomatic. ${ }^{2}$ Vertical and perinatal transmission yield the most severe outcomes of the Zika epidemic. Neonatal Zika infection can lead to congenital Zika syndrome (CZS), which includes a canopy of congenital defects: microcephaly, hypertonia, arthrogryposis, blindness, deafness, and developmental abnormalities. ${ }^{3,4}$ Since the initial stages of the epidemic, USAID has implemented its Zika response in partnership with IPs in the region. The USAID Zika response comprised four lines of effort, all contributing toward prevention of transmission and amelioration of impact, including: (1) SBC communication; (2) vector control; (3) service delivery; and (4) research and innovation. ${ }^{+}$More than 20 countries in Central and South America and the Caribbean were part of the USAID Zika response. ${ }^{\ddagger}$

\section{SBC within the USAID Zika response}

Throughout the USAID Zika response, SBC efforts included activities or interventions that seek to change health-seeking behaviors by raising awareness, reducing misinformation, promoting social norms that enable

\footnotetext{
"While the WHO declared the Zika public health emergency over in November 2016 due to the decreased incidence of Zika virus cases within the region, new reports indicate that Zika continues to pose a threat to public health around the world.

${ }^{+}$Gender integration and community engagement were crosscutting technical areas that informed the USAID Zika response.

‡For more information on the USAID Zika response, visit: https://www. usaid.gov/global-health/zika/where-we-work.
}

these behaviors, and addressing the barriers that prevent individuals, families, and communities from practicing behaviors to improve health outcomes. ${ }^{3,5}$ Examples of SBC activities in the USAID Zika response include approaches that: increase uptake of Zika prevention

THROUGHOUT THE USAID ZIKA RESPONSE, SBC EFFORTS INCLUDED ACTIVITIES OR INTERVENTIONS THAT SEEK TO CHANGE HEALTH-SEEKING BEHAVIORS BY RAISING AWARENESS, REDUCING MISINFORMATION, PROMOTING SOCIAL NORMS THAT ENABLE THESE BEHAVIORS, AND ADDRESSING THE BARRIERS THAT PREVENT INDIVIDUALS, FAMILIES, AND COMMUNITIES FROM PRACTICING BEHAVIORS TO IMPROVE HEALTH OUTCOMES.

behaviors; increase demand for and utilization of commodities and services among target populations (e.g., mosquito repellants); shift attitudes by addressing social norms (e.g., condom use during pregnancy); and reduce barriers to consistent practice of prevention behaviors (e.g., building skills to effectively remove vector breeding sites). Approaches used in the USAID Zika response are outlined in Table 1. The response also focused on building the capacity of organizations and governments to implement and manage SBC program implementation. The capacity-building approach centered on technical assistance to ministries of health and other stakeholders to improve the strategic design and implementation of SBC programming. 
TABLE 1 OVERVIEW OF SBC APPROACHES IN THE USAID ZIKA RESPONSE

\begin{tabular}{|c|c|c|}
\hline SBC APPROACHES & DE & ¿CRIPTION OF APPROACH IN THE ZIKA RESPONSE \\
\hline \multirow[t]{3}{*}{ Mass and social media campaigns } & $\bullet$ & Regional mass media campaigns (TV, radio, print media) \\
\hline & - & Social media peer educators \\
\hline & $\bullet$ & Country-level mass media/risk communication campaigns \\
\hline Engagement through community action & $\bullet$ & Community dialogues, care groups, mobilization campaigns \\
\hline \multirow[t]{4}{*}{ Engagement through schools } & $\bullet$ & Teacher training for Zika prevention \\
\hline & - & School campaigns/events \\
\hline & - & Formation of youth leaders for peer-to-peer education \\
\hline & - & Promotion of school-based vector surveillance \\
\hline \multirow[t]{2}{*}{ Interpersonal communication } & - & Outreach through household visits using community health volunteers \\
\hline & - & Campaigns via employed vector-control technicians \\
\hline \multirow[t]{4}{*}{ Capacity building and technical assistance } & - & Direct assistance to governments: risk communication national plans \\
\hline & - & Development of guidelines, tools, and curricula for regional use \\
\hline & - & Direct assistance to IPs \\
\hline & $\bullet$ & Capacity-building workshops (e.g., interpersonal communication) \\
\hline
\end{tabular}

\section{Extracting the lessons learned of SBC programming within the USAID Zika response}

Breakthrough RESEARCH was charged with extracting the key lessons learned from USAID, IPs, and other stakeholders within the USAID Zika response. From this effort, Breakthrough RESARCH was asked to develop recommendations for USAID and other key bilateral and multilateral stakeholders for future public health emergency SBC programming. The recommendations cover the areas of design and implementation and monitoring, evaluation, research, and learning (MERL). While focused on the SBC line of effort, there is recognition within USAID and among partners that both the service delivery and vector-control efforts also contribute toward behavior change for Zika prevention as they interact with target priority populations within clinic settings and in communities. Breakthrough RESEARCH therefore engaged with vector control and service delivery IPs who also contribute to behavior change. Breakthrough RESEARCH sought to answer the following guiding research questions:

1. What were the successes, challenges, and gaps in designing, implementing, and adapting SBC programming in the USAID Zika response?

2. What were the successes, challenges, and gaps in generating and using data and evidence in SBC programming in the USAID Zika response?

3. What do the successes, challenges, and gaps of the USAID Zika response's SBC programming imply for future health emergency responses? 


\section{METHODOLOGY}

Four components contributed to this documentation exercise: (1) an online assessment of SBC, vector control, community engagement, and service delivery IPs' utilization of key technical guidance documents developed as a result of a prioritization process of prevention behaviors; (2) a systematic comparison of quantitative data collection instruments used by SBC and community engagement IPs to collect data on Zika knowledge, attitudes, and practices (KAP); (3) qualitative stakeholder interviews; and (4) a review of key lessons learned synthesis documents developed by SBC partners as part of end-of-program documentation efforts.

\subsection{Online assessment of utilization of technical guidance}

In August 2018, a short, 18-question survey was distributed to USAID IPs asking questions pertaining to their perceptions of two key technical guidance documents for SBC that were developed and disseminated by Breakthrough ACTION+RESEARCH in early 2018 to support IPs. The first technical document outlined seven prioritized behaviors for Zika prevention. It documented existing evidence of the prevention efficacy of each behavior as well as considered contextual factors that may facilitate or inhibit their feasible practice by the target beneficiaries. The second technical document provided "how to" details for each behavior to maximize their effectiveness. ${ }^{6,7}$ The survey was distributed to all USAID Zika response project directors ( $\mathrm{HQ}$ ) as well as to SBC points of contact for partner organizations ( $\mathrm{HQ}$ or regional). The survey was sent to 66 individuals, mostly at national/international $\mathrm{HQ}$ and regional offices, requesting they forward on the survey link to their field teams. The survey included both open- and close-ended questions. A total of 50 responses were received across the following settings: the Dominican Republic, El Salvador, Guatemala, Nicaragua, Panama, Paraguay, and the United States. Most respondents (62\%) worked in the SBC technical area, while the remainder worked in service delivery.

\subsection{Systematic comparison of KAP data collection instruments and methods}

Throughout the USAID Zika response, SBC technical experts relied on KAP data for monitoring ideational and behavioral indicators. The Breakthrough RESEARCH project carried out a comparison of survey instruments to assess the extent to which the KAP surveys were comparable and the rigor of the methodology used for sampling and data collection. Implementing partners who contributed survey instruments were: Breakthrough RESEARCH, Global Communities, International Federation of Red Cross (IFRC), Save the Children, Population Services International (PSI), Medical Care Development International (MCDI), Sustainable Sciences Institute (SSI), United Nations International Children's Emergency Fund (UNICEF) Honduras, Care Peru, Care Ecuador, and Health Communication Capacity Collaborative (HC3). Survey and sampling methodologies were reviewed using partner project documentation, which varied in level of detail. Some IPs shared field guides and standard operating procedures, while others shared short descriptions of the sampling and data collection methodology.

\subsection{Qualitative evaluation}

A qualitative evaluation was carried out using in-depth interviews with key informants from three categories of stakeholders: USAID Zika response team members at $\mathrm{HQ}$ and in USAID missions; USAID SBC, service delivery, and vector-control IPs; and ministries of health. Participants were asked about their perceptions of the successes, challenges, and gaps in the design and programming of SBC activities for Zika disease prevention. Specific dimensions in the interview guide included existing SBC capacity, stakeholder coordination, and generation and use of evidence. Interview data were analyzed by themes aimed at identifying, documenting, and validating lessons learned and key outcomes of the USAID Zika responseboth expected and unexpected. 
Participants who represented a stakeholder institution in the USAID Zika response and who were willing to participate in an interview were included. Stakeholders were initially identified by USAID as the most relevant and knowledgeable about USAID SBC programming. A small number of additional interviewees were identified using a snowball sampling method. Stakeholders from six implementing countries (Dominican Republic, El Salvador, Guatemala, Honduras, Jamaica, and Peru) plus regional offices and $\mathrm{HQ}$ were included in this study. Organizations from which interviewees were selected include: Abt Associates (Zika Airs Project [ZAP]), CARE (Juntos Contra el Zika), Global Communities (Nuestra Salud), IFRC and Save the Children (Community Action on Zika [CAZ] Project), Johns Hopkins University Center for Communication Programs (Breakthrough ACTION), Medical Care Development International (MCDI; Project ZICORE), ministries of health in four of the implementing countries, PSI/Pan American Social Marketing Organization (PASMO), UNICEF, University Research Company (Applying Science to Strengthen and Improve Systems [ASSIST] Project), and USAID/Washington and USAID Missions.

Contact information for identified stakeholders was obtained from USAID and emails were sent to each informant to indicate the objectives of the evaluation, the purpose of the interview, the proposed schedule for the interview, and an enclosed informed consent document. Once the key informant agreed to participate, an interview date and time was established. Interviews were conducted between January and April 2019. If a face-to-face interview was not possible, an online video interview took place via video conferencing using Zoom (https://zoom.us) or Skype (https://www.skype.com/ en/). Interviewees were read the institutional review board-approved consent form and oral consent was obtained. Once consent was given by the participant, a trained interviewer conducted the interview. Interviews were conducted in either English $(n=27)$ or Spanish $(n=50)$, depending on the interviewee's language preference. Three interview guides were used: one for IPs, one for USAID staff, and one for ministry of health personnel.

A total of 77 interviews were completed, of which 48 were conducted in person and 29 were conducted remotely via Zoom or Skype (see Appendix Table 1 for interviewee representation). In-person interviews were audio-recorded using a digital voice recorder. Zoom and Skype interviews were recorded via the software interface. The interviews had an average duration of 95 minutes. The interview audios were transcribed within 72 hours of the interview's completion. Interviews were transcribed in the language in which the interview was conducted (English or Spanish) by a native speaker.

A member of the research team then reviewed each transcript for quality control.

Using Dedoose (https://www.dedoose.com/) software, the research team began systematic coding of transcripts. A predetermined list of potential codes was used, including primary codes following the topics covered in the semi-structured interview guide with secondary codes for sub-themes. The team also allowed for emergent codes to develop during the coding process, with the first 15 percent of transcripts being independently coded by two people in order to test intercoder reliability. The two coders from the research team for each interview met to discuss coding decisions and adjudicate differences, and the full team established an expanded codebook. Once initial coding was completed, thematic analysis was conducted by a team of six researchers during a 3-day workshop.

\subsection{Documentation review}

As the Zika Response wound down, USAID and Zika IPS came together in a series of efforts to reflect jointly as well as individually about the lessons learned throughout the USAID Zika response. This document was informed by several documentation efforts carried out during the last few months of the response, namely a report based on the Zika Share Fair held in April 2019 in the Dominican Republic, ${ }^{8}$ a report based on the systematization of community mobilization and engagement experiences held in Ecuador in May 2019, ${ }^{9}$ a systematization of the essential elements for community-based arbovirus prevention and control developed by $\mathrm{MCDI},{ }^{10}$ and individual projects' lessons learned and success stories. These select documents were chosen for inclusion in collaboration with USAID. 


\section{RECOMMENDATIONS}

This section provides eight recommendations for SBC programming in emergency responses based on lessons learned in SBC programming within the USAID Zika response. For each, the lessons learned quotes from the data-collection process are used to substantiate the recommendation. The eight recommendations span two broader categories: (1) recommendations for strategic design and implementation of SBC programming; and (2) recommendations for MERL.

\subsection{Strategic design and implementation of SBC programming}

\section{Recommendation 1}

A strong coordination for SBC in the emergency response is needed to ensure collaboration, harmonization, and joint SBC planning and implementation. Establishing a multi-tiered platform of working groups at $H Q$, regional and country-level consisting of key stakeholders early in the emergency response furthers the alignment and harmonization of SBC planning and implementation. Where possible, existing structures should be leveraged for country-level coordination.

Many IPs and country-level USAID staff discussed challenges in coordination, especially at the beginning of the response, resulting from the large number of partners involved. Participants perceived that there was a lack of a process for meaningful collaboration at the earliest stages, which led to potential for duplication of efforts and inconsistency of SBC messages across IPs. In countries with multiple IPs, and therefore a larger number of stakeholders with whom to coordinate at the country level, it was particularly challenging to bring all stakeholders together.

\footnotetext{
I feel that there are too many [IPs/ stakeholders] in the [Zika] response... and when we all arrived, [there being many partners] didn't help much. However, now we are much better at coordinating after everything that happened at the beginning....
}

Stakeholders reported that coordination was greatly strengthened across the first year of the response and occurred at four levels: (1) response-wide coordination from Washington, D.C. through periodic partner meetings involving all technical areas; (2) coordination among $\mathrm{SBC}$ and community engagement partners at $\mathrm{HQ}$ in Washington, D.C.; (3) country-level coordination among all technical areas through stakeholder meetings convened monthly by USAID Missions and involving IPs and sometimes country's ministry of health, as well as SBCspecific working groups in some countries; and (4) local coordination among IPs, community stakeholders, and local government administrations as part of implementation of community engagement activities. Country-level coordination started earliest; USAID and partners were able to leverage cross-sectoral working groups (mesas técnicas) where they already existed. This was the case in Honduras, where the working group also included the Ministry of Education, various arms within the Ministry of Health, and non-U.S.-government-funded stakeholders. Honduras also had a pre-existing SBC working group (mesa técnica de comunicación) that was leveraged for coordination during the Zika response. In most countries, working groups were established by USAID to coordinate activities among partners and to provide opportunities for sharing experiences and strengthening programmatic practices. They were primary avenues for IPs to update each other on what they were working on and find opportunities for synergy, avoid duplication, share SBC best practices, and learn from one another. When country-level leadership and decision-makers attended, it enhanced the meetings' productivity and impact.

...given the number of partners, [USAID] coordination has been very strong through our Mission colleagues. They have been crucial in coordinating all the partners. With the number of partners, [they achieved] a coherent sort of response where every partner has a role. I think that we were able, to the degree possible, to leverage existing relationships in countries [to achieve this coordination]. 


\section{At the beginning, working groups were formed. They already existed in [our country], but in other countries we formed them with the support of USAID. The ministries really ended up guiding the working groups and agreeing on the content and perspectives. There is a strong coordination between them and the different partners.}

-USAID, Field

Guatemala is a successful case study of how the country-level Zika SBC working group played a crucial role in updating the Ministry of Health's technical guidance for Zika prevention. The working group meticulously reviewed SBC technical guidance documents produced during the second year of the response, specifically, the Technical Specifications Content Guide for Behaviors with High Potential to Prevent Zika. These guidance documents were adapted to the Guatemalan context, aligned with Ministry of Health requirements, and institutionalized to become official Ministry of Health guidance.

An SBC working group based in Washington, D.C. was formed in Year 2 of the response, after USAID determined a need for greater coordination and harmonization among global IPs. Breakthrough ACTION, the USAID global flagship project for SBC implementation, served as secretariat for the working group. The group met approximately every two months for half a day in Washington, D.C., with in-person participation from U.S.-based staff and virtual participation from teams based in Latin America and the Caribbean. ${ }^{11}$ Many of the projects were centrally funded and managed from $\mathrm{HQ}$ offices in Washington, D.C., which made coordination at this level crucial to reinforce the coordination that was already occurring at the country level. When HQ IP staff obtained a better understanding of the work and scope of other partners, coordination at the country level was more readily achieved as they already had buy-in from their HQ's leadership.

Despite initial challenges, once internal coordination efforts within the response were established, they were viewed as essential to the success of an effective Zika response.

...everyone seemed really focused on trying to work together in a way that wasn't the case in the Ebola response [and] wasn't the case with the Haiti earthquake. It just seemed like everyone was like, 'No, let's try and do this better this time and really work collaboratively.' So that was something very positive out of this response.

-IP, Regional

Without a doubt, working groups are platforms that have been and continue to be created. Some of them are organized through partners, which has allowed for a rich exchange of experiences. These platforms have without a doubt allowed sharing experiences and a technical strengthening of the different organizations that are part of this partnership.

-IP, Guatemala

One community-engagement IP in particular recognized that coordination at the community level as part of implementation of community engagement activities was central to ensuring community ownership and coordination with local government. ${ }^{10}$ Formation and development of community health committees was identified as a best practice to ensure community-level participation and coordination. Where implemented, these committees were usually convened by a representative of either the ministry of health or the municipal government, and served not only as a forum for the governmental conveners to coordinate with other actors in the field, but also to organize and mobilize the actions of the community. An important key for success was to set and maintain regular meeting times, typically monthly. It was also crucial to work with the convener to set the agenda to ensure that appropriate input from members could be requested as well as to provide programmatic updates and information.

In sum, a primary lesson learned in the area of coordination is the supportive role that SBC technical working groups at regional, country, and community levels can have in ensuring partner coordination and promoting collaborative efforts, in addition to USAID partner meetings involving all technical areas. ${ }^{11}$ The regional SBC working group enabled regional IP leadership coordination, which further enabled country-level coordination led by country-level working groups. Stakeholder collaboration throughout the Zika response has been recognized as 
"unprecedented" by all interviewed stakeholders and was greatly valued. Nonetheless, participants also note that collaboration could have been improved with earlier convening of the Washington, D.C.-based SBC working group. This would have allowed an earlier alignment of SBC strategies based on prioritized behaviors and partner coordination starting at the $\mathrm{HQ}$ level, avoiding inconsistent and presumably less effective messaging in early days.

\section{Recommendation 2}

At the outset of a public health emergency response, determine priority behaviors through a participatory process with all stakeholders. This process may be more effective if facilitated by a partner with SBC technical expertise and include a review of the most robust evidence available as well as discussions of contextual considerations that may impede behavior change.

At the beginning of the Zika epidemic, the lack of information on virus modes of transmission, effective prevention behaviors, and consequences of infection was perceived as a major challenge among all respondents. The gaps in scientific knowledge hampered stakeholders' decision-making regarding the interventions that would be most effective and which prevention behaviors and public health messaging were most relevant for this disease. Zika was perceived to be different from other mosquito-transmitted arboviruses in the region, with many unknowns, particularly as information about Zika and its consequences was rapidly evolving during the response.

\section{It was a lot more challenging with \\ Zika...the behaviors that we understand now [as being important for prevention] were not necessarily the behavior we understood early on, because we weren't sure [of the] level of infectivity in terms of sexual transmission. We weren't quite sure if the disease had changed or Zika was more infectious. We just didn't know a lot.}

-USAID, HQ
Zika congenital syndrome, the sexual transmission piece, and so on, which came later.... The most challenging piece of working on Zika the first couple of months [was that] things had to happen really quickly but there was not much for clear-cut scientific direction.... So we had to wait, for instance, for some of these committees to convene, look at the evidence, and make recommendations, which then we could take into account as part of the guidance that goes out to a global level. But essentially...I think [for] the other diseases the science is a bit clearer; even for Ebola, I think the transmission modes are clearer.

$-I P, H Q$

In the early stages of implementation, partners were focused on increasing the targeted populations' knowledge of Zika's transmission, symptoms, and health consequences, as well as promoting a large number of prevention behaviors. A review of USAID-supported risk communication materials used during the first year of the response showed that more than 30 variations of Zika preventive behaviors and messages were being promoted by different IPs within and across countries. In addition, not all were supported by evidence regarding their effectiveness in prevention of arboviruses (see Box 1).

\section{BOX 1 EXAMPLE OF PREVENTION BEHAVIOR NOT SUPPORTED BY EVIDENCE}

Mosquito coils are sold commercially in the Latin American region and their use was promoted to prevent mosquito bites. According to multiple studies, mosquito coils are not effective for personal protection. ${ }^{12,13} \mathrm{~A}$ meta-analysis found that mosquito coils could, in fact, be associated with higher risk of dengue. ${ }^{14}$
At the start of Year 2 of the response, given the large number of prevention behaviors being promoted by partners, USAID saw the need to develop and implement a process for prioritizing behaviors that would be most effective for prevention using the best available evidence and with consideration for the feasibility of the behaviors 


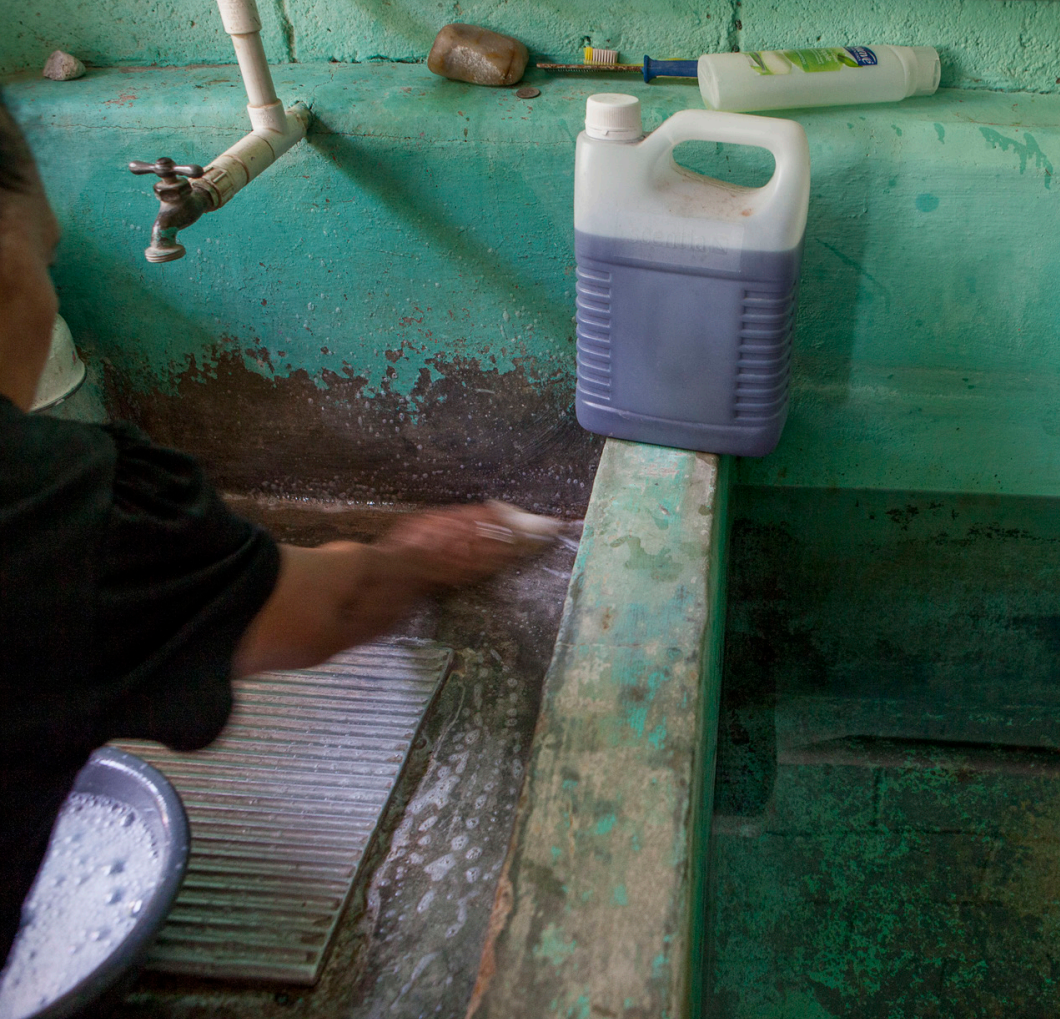

(C)2017 Brendan Bannon/USAID, Courtesy of Photoshare

being implemented by individuals in context. This process was developed in a partnership between USAID and the USAID-supported Breakthrough ACTION+RESEARCH projects, with collaboration from USAID-supported IPs participating in the Zika SBC Working Group. The prioritization process resulted in two technical documents: Zika Prevention Behavior Matrix ${ }^{6}$ and Technical Specifications Content Guide for Behaviors with High Potential to Prevent Zika. ${ }^{7}$ The prioritizing process was collaborative and was validated and disseminated as part of the SBC Technical Working Group. A full description of this process and results have been published elsewhere. ${ }^{15}$ The prioritization process was considered a very effective approach for improving and complementing SBC programming approaches across partners.

\begin{abstract}
I think we saw that in the Zika case where initial messages went out and then as more partners were brought in we were able to get more data and do those literature reviews, get that evidence and then we started to tighten the messages because it was a danger that $\mathbf{1 5}$ different organizations with $\mathbf{5 0}$ messages and even if we had the same theme it was very confusing to the public. So we worked very closely with all of the Zika implementing partners, but I will say in particular Breakthrough [RESEARCH] and Breakthrough ACTION and you know the vector partners and the Red Crosses and the other organizations as we came together as a technical working group to get together on the same page and make those decisions and decide on the key messages and what [will] be less of a priority and what issues we need to leave behind and so on.
\end{abstract}

$$
-I P, H Q
$$

The Zika Prevention Behavior Matrix created from this process outlined seven prioritized behaviors, including two personal protection behaviors, three household and community vector-control behaviors, and two enabling behaviors (see Table 2). The accompanying Technical Specifications Content Guide provided specific "how to" information needed in order to promote effective

TABLE 2 OVERVIEW OF CATEGORIES AND BEHAVIORS IN THE ZIKA PREVENTION BEHAVIOR MATRIX6

\begin{tabular}{ll} 
CATEGORY & BEHAVIOR \\
\hline Personal protection & $\begin{array}{l}\text { Application of mosquito repellent (DEET, Picaridin, IR3535, or oil of lemon eucalyptus only), using each prod- } \\
\text { uct as directed for the duration of pregnancy to reduce risk of Zika transmission through mosquito bites. } \\
\text { Use of condoms to prevent sexual transmission of Zika in pregnancy. }\end{array}$ \\
$\begin{array}{l}\text { Household and } \\
\text { community vector } \\
\text { control }\end{array}$ & $\begin{array}{l}\text { Regularly removing unintentional standing water both inside and outside the house and in communal areas. } \\
\text { Covering water storage containers at all times with a cover that is tight-fitting and does not warp or touch } \\
\text { the water. }\end{array}$ \\
& $\begin{array}{l}\text { Eliminating mosquito eggs from walls of water storage containers weekly. } \\
\text { Enabling behaviors }\end{array}$ \\
& $\begin{array}{l}\text { Seeking prenatal care to monitor pregnancy and discuss Zika risk and prevention. } \\
\text { Seeking counseling from a trained provider on modern family planning methods if not planning on getting } \\
\text { pregnant. }\end{array}$
\end{tabular}


prevention behaviors. For example, details were provided about how to properly cover water barrels (specifically, that the container be completely sealed around all its edges, that the covers not dip into the water, and that rainwater not be allowed to accumulate on top). This level of specificity for each prioritized behavior allowed for more focused and effective SBC messages. The guides also indicated that not all prevention behaviors should be promoted for all targeted populations. For example, while skin repellents are highly effective to prevent mosquito bites, given the relative cost in some settings in the region and the need for repeated application throughout the day, it was determined that this prevention message should be promoted only for pregnant women., ${ }^{6,7}$

With the prioritization guides in hand and IPs' subsequent reviews of their SBC messages, recommendations were adjusted to their local contexts. Most SBC partners chose to promote a subset of the behaviors that best fit their project's scope, objectives, and target populations. For example, some partners chose not to include family planning referrals as part of their community-level activities, as this health area was not a standard component of their implementation.

IPs perceived that the behavior prioritization also facilitated the volunteers' work, as fewer and more specific messages needed to be conveyed.

When [partner] arrives, they focus on working only with six key messages which can generate behavioral change. So now, from May until today, we have had six months of working only with these messages. And it is more effective, because people no longer have to be talking about all the Zika information, and can only focus on these messages....

-IP, Honduras

Because of the training, and with the adoption of the six key behaviors, we could see in our last monitoring visits that volunteers were more comfortable delivering messages.

-IP, Honduras

Similarly, the prioritization process affected the delivery of messages in the regional mass media campaign rolled out throughout the region, which was significantly refined as a result of the technical guidance that emerged. The first round of the campaign focused on transmitting knowledge about Zika, which respondents thought was probably appropriate for a new disease people knew nothing about, but probably insufficient to lead to behavior change. By the second year, the campaign's key messages were geared toward the prioritized behaviors, addressing key elements that make each behavior effective (see Box 2). In this way, respondents perceived the mass media campaigns as appropriately evolving.

\section{BOX 2 EXAMPLE OF SPECIFICITY NEEDED TO IMPROVE EFFECTIVENESS OF BEHAVIORS}

Early in the Zika response, it was recommended that households clean their water storage containers. After the prioritization, four specific instructions were provided based on available evidence and contextual factors to assure the behavior was effective, including: 1) the frequency of cleaning; 2 ) the specific containers that needed cleaning; 3 ) the need to use a scrub brush; and 4) how to properly apply bleach and/or non-ammonia detergent.

Despite the successes of introducing the behavioral prioritization process, IP participants described the challenges of shifting programming to align with the technical guidance. Materials that had already been created and undergone the long approval process with pre-testing and ministry of health approval had to be readjusted. All stakeholders expressed the importance of remaining flexible throughout the implementation process.

\section{When we finally had a set of materials that could be used for mobilizing people in the community, we're finally done with that, with the pre-testing, with the approval with a government-which was a big deal-and then we had this new development because there's new scientific discovery or whatever...so we had to adjust. So we had to go back and think, 'Okay, let's just try to move on with this and just try to include [the new evidence] as we go along.' So those were the dilemmas we had.}


The evidence-based, collaborative process of prioritizing behaviors is widely recognized as a strategic and implementation success in the USAID Zika response, even though there was widespread acknowledgment that an early process would have been better. Therefore, a significant lesson learned from the Zika response is the need for a strategic planning process at the beginning of a public health emergency, with an evidence-based, collaborative behavior prioritization process. Even in the case of more mature outbreaks or epidemics, a behavior prioritization process is still recommended, as new scientific evidence may have emerged that impacts what behaviors are prioritized or how they need be practiced to be fully effective. The process also assists in creating consensus, harmonization, and buy-in across partners involved in the response, as it recognizes that programmatic decisions should be evidence-based and thoroughly weighed against contextual considerations.

In addition, the process of behavior prioritization was a key capacity-building element for IPs. By coming together and contributing to the Zika Prevention Behavior Matrix and accompanying Technical Specifications Content Guide, field staff were able to access and understand the evidence for each behavior, deliberate about what was feasible in their context, and delineate the specific actions that make each behavior effective for reducing risk of Zika transmission. As was noted by many participants (see Box 3 ), the process of prioritizing behaviors and applying the resulting technical guidance to adapt SBC programming posed an opportunity for institutional capacity-building among SBC partners.

I remember [name withheld] saying, 'Do you think if we did this prioritization activity it could have any real impact since by the time it would be done people would be moving into their third year?' My feeling was, it may not have an enormous [impact] but if nothing else it starts to build capacity in all of our partners to understand that this is an important step. Especially when there's lots of different partners....

-USAID, HQ

Overall, these technical guidance documents resulting from the prioritization process were well-received by partners, as they helped narrow down the focus of SBC

\section{BOX 3 ONLINE SURVEY OF TECHNICAL GUIDANCE UTILIZATION}

An online survey of IPs' perception and use of the Zika Prevention Behavior Matrix and Technical Specifications Content Guide for Behaviors with Highest Potential to Prevent Zika showed that:

- The majority (62 percent) of participants had received both materials in the past six months.

- Most participants reported receiving the Behavior Matrix and Technical Specification Guide via USAID email (30 percent), a colleague (28 percent), a Zika SBC Working Group meeting (18 percent), or another event (18 percent).

- Half (50 percent) of respondents described utilizing the materials to adapt some aspect of their work, and more than one quarter (28 percent) of participants reported they had used materials to direct discussions with national or regional stakeholders.

- About one third (34 percent) of participants stated they had participated in organizational meetings to discuss the utility of the materials and 30 percent reported they had participated in organizational meetings to plan integration of the materials into their organizations' work.

- More than half (58 percent) of respondents reported that they used the materials to refine existing prevention messages to be promoted by their organization.

Respondents felt the material provided clarity and specificity on key prevention priorities. They were also perceived as having assisted partners in promoting focused, homogenous approaches to Zika virus prevention. One respondent stated, "This document has helped inform how we talk about our activities and the Zika prevention behaviors to ensure all partners have one voice." 
efforts and prioritized messaging across partners/programs through an evidence-based approach (see Box 3). Respondents felt the main challenge with the behavioral prioritization matrix was that it was not developed until midway into Year 2. At this point, the epidemic had begun to wane and many partners' programs were already being implemented, posing challenges in adapting existing materials that had already undergone a lengthy approval process. Additionally, respondents felt that the matrix, being a general guide, did not account for context-specific factors such as political climates, cost of materials, and cultural acceptance of the behaviors being promoted.

\section{Recommendation 3}

$S B C$ should be recognized as a crosscutting line of work and integrated into other technical areas within public health emergency responses.

Another widely acknowledged lesson learned is that SBC is a cross-cutting approach that adds value when incorporated into other technical areas. SBC and vector-control IPs reported a collaboration between them that developed organically during implementation. For instance, while vector-control IPs - those whose mandate included the control and surveillance of the Aedes aegypti mosquito-were not charged with SBC by design, IPs told a consistent story that community engagement and interpersonal communication with household members became an important element of their programming. Vector-control technicians applying larvicide to water storage containers during home visits recognized that their presence in the household represented an additional opportunity to promote prevention messages and practices such as the elimination of mosquito eggs from the walls of the containers. Vector-control IPs established a collaboration with SBC IPs to integrate elements of SBC into their work, particularly in strengthening their interpersonal communication approaches during home visits. Likewise, SBC partners were able to benefit from vector-control IPs' entomological expertise during the behavioral prioritization process that was described in Recommendation 2. Entomologists from vector-control IPs provided critical input to help SBC partners define how each vector-control behavior should be performed to maximize effectiveness. As collaboration between service-delivery IPs and SBC areas was not as deeply engrained, this was perceived by IPs as a missed opportunity for collaboration. As such, IPs across technical areas believed that SBC would have been more effective as an integrated, cross-cutting approach, rather than as a siloed, programmatic area.

When you provide an SBC lens to all the
different lines of effort, you're able to
have a multiplier effect and have an impact in
actually changing behavior. So it's important to
break down those silos and see, 'How can we
take advantage of these things that are going
on?'

$-\mathrm{IP}, \mathrm{HQ}$

\section{Recommendation 4}

Develop solutions informed by participatory design methods, such as human-centered design (HCD), within the mix of SBC strategies, given their potential advantages for public health emergency responses.

Interviewed partners identified a need to better understand and plan for behaviors that may be impeded by structural and cultural barriers. Implementing partners in Jamaica piloted an HCD process to address household water storage practices as a source of breeding sites (see Box 4 for a definition of HCD). This process resulted in a range of prototype solutions, including designs for new water barrel lids that overcame common barriers to use. Despite the application of this innovative and promising process, the project did not have sufficient time to develop these prototypes into fully implementable solutions within the timeframe of the Zika response..$^{16,17}$ While not using a formal HCD methodology, another IP in Nicaragua developed a prototype for a water barrel lid to prevent mosquito breeding. This prototype incorporated formative research and community input about what made container covers difficult to use well and produced a highly promising alternative to the commercially available water storage container covers. ${ }^{16,17}$

\section{BOX 4 WHAT IS HCD?}

Human-centered design works through a formative process that consists of jointly generating ideas for addressing behavioral barriers and programmatic gaps. It iteratively works with target populations to design, test, and refine jointly determined solutions, interventions, and programmatic approaches. ${ }^{18}$ 
Early and more extensive experiences with HCD, or other highly participatory design methods, may have helped overcome barriers to behavioral adoption. Since the prototypes are developed and iterated upon with the community's input, solutions are more likely to address any potential community concerns, fears, mistrust, or outright opposition. Relatedly, the participatory approach promotes a sense of collective community ownership of the solutions developed, potentially influencing positive social norms regarding the adoption of behaviors.

An advantage of HCD or other participatory processes is that they can often be implemented quickly and as such adapted to fit within the timeframe of an emergency response. That said, one IP's experience shows that the HCD process requires substantial human resources, as ideally, the various stakeholders are involved in every step of the HCD process (i.e., formative research, design, testing and refining). During outbreaks when all stakeholders are working under time-scarce conditions, HCD processes should identify the key decision points where all stakeholders' input is most essential and prioritize those instances when requesting their time and participation in the adapted HCD process. Key decisions points would need to be defined together with stakeholders, but could include defining the scope, geographic areas, and audiences of the formative research; discussing insights and determining which to prioritize for design and testing; and at several points in the iterative prototype design and refinement process. Decisions during the latter stage may include what to prototype in the first place, whether something is ready to move to a pilot phase, and whether to discontinue a prototype.

\section{Recommendation 5}

Given the constraints of emergency programming, ensure attention is given to identifying and mobilizing the appropriate SBC expertise within projects and consider including an IP that can provide SBC technical assistance to partners and governments should they need it.

While IPs reported strong SBC technical expertise at $\mathrm{HQ}$, some struggled to identify and recruit local staff with the most appropriate SBC experience, particularly in the early stages of implementation.

\footnotetext{
...when the project was starting...the biggest challenge was that...we couldn't find an SBC person at the regional level and even less so at the country level. So at the country level we hired people, either
}

\section{consultant or staff, who were actually commu- nications people. Communications is not the same as SBC. There is a lot of overlap, but it is not the same thing. And all of the people were communication people and I had to train all of them on what is SBC and some people took it in and accepted it and ran with it and others not as much.}

-IP, HQ

As the quote above illustrates, technical expertise at the regional and country level was challenging to secure, and SBC was often confused with "communication," which is a related, but different field. Communication can be used as a part of social and behavior change programming, in an approach called social and behavior change communication (SBCC). Managing SBC programming requires a broader understanding of the behavioral sciences, of the multiple approaches that can be used for changing behaviors and how to carry out those strategies in an evidence-based, systematic fashion.

In addition to the challenge of finding staff with adequate SBC expertise, stakeholders discussed challenges training community health volunteers. Community engagement IPs mobilized hundreds of frontline community health volunteers and employed health promoters to conduct household visits to give their neighbors information about how to prevent Zika. These home visits provided a unique opportunity for individuals to express their concerns and doubts about Zika, clarify myths, and observe their fellow community members correctly performing prevention behaviors. Despite this, IPs in some settings reported that the community health promoters and volunteers struggled to get people to change their behavior. ${ }^{8}$ Participants recognized the need to provide effective training for health promoters and volunteers delivering behavior change programming in the field to ensure harmonization of messages. Building SBC capacity at the community level required continuous training to ensure their programs' staff, community health promoters, and community health volunteers were able to implement effective SBC strategies. Participants felt that without extensive training, staff and volunteers would be less able to implement effective strategies in the community, leading to potentially ineffective programmatic effort.

Breakthrough ACTION provided SBC capacity-strengthening during the USAID Zika response. To determine which capacities to strengthen, Breakthrough ACTION and 
USAID gathered insights through online surveys, one-onone meetings, and direct observation with ministries of health and IPs during field visits. ${ }^{8}$ In addition, by facilitating the SBC Working Groups in each country and in Washington, D.C., they were able to keep a broad view of the shared challenges in implementation. This helped them facilitate discussions and tailor technical assistance. Direct observation in the field revealed that improving interpersonal communication (IPC) could improve health promoters', community health volunteers', and paid vector-control staff members' engagement with community members and help communities prevent Zika. To strengthen local SBC capacity and the IPC skills of frontline workers, Breakthrough ACTION developed a training curriculum that adapted the GATHER ${ }^{\S}$ approach to the context of a household visit. Breakthrough ACTION trained nearly 1,000 frontline community volunteers, health promoters, vector-control workers, trainers, and program coordinators involved in the USAID Zika response on using this approach to share technical information while fostering a sincere rapport with households.

${ }^{\S} \mathrm{A}$ mnemonic that stands for: Greet the person in a friendly and respectful way, Ask the person about their needs, Tell them about what they can do, Help them to find a solution, Explain by demonstrating how the practice should be done, and Review what was discussed.
In response to other needs identified by USAID, IPS, and Breakthrough ACTION, additional capacity-strengthening workshops covered the use of behavioral data to make midcourse program adjustments and utilize innovative SBC approaches. Other workshops introduced country counterparts to Breakthrough ACTION's SBC Flow Chart-an innovative, systematic process that combines the principles of communication, behavioral economics, community engagement, and HCD - to strengthen SBC programs and activities. ${ }^{16}$

IPs were also able to provide SBC technical assistance within their own projects, resulting in a more sophisticated understanding of SBC programming at local levels. One interviewee from a regional project described their team members' progression from a unidirectional model of prevention work to one of engaging the communities to lead in their own prevention efforts, incorporating a fuller, more nuanced understanding of SBC.

Before, when I went to [local offices],
they would show me all their flyers and
be very happy with their flyers. Now when I go
to [local offices], they tell me, 'Oh, we're doing
this because we think that this doesn't have an
effect and we want people to be able to do this
behavior.' Or, 'We're not wanting to lead, like
just go in and do something for people; we

(C)2017 Brendan Bannon/USAID, Courtesy of Photoshare

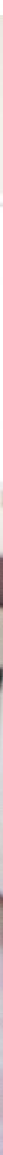


want them to lead it so that when we leave, they're still doing that,' or, 'We want them to understand.' Like they used to do community cleanups where they would just do the cleanup and not bother to explain what the risk is, but now they're going through with every cleanup they're mapping with the communities, what the risks are, they go and find the mosquitoes so the communities can understand the reasons behind why they're doing something and getting there. Now [local office] is getting invited [by the community] to go along to clean out rather than just going in and cleaning up for other people.

-IP, Regional

UNICEF, a partner in the USAID Zika response, also developed an institutional way to increase SBC capacity in the region by partnering with local universities to develop a diploma program for risk communication in two Central American countries. UNICEF considered the development of this diploma program a great success that contributes to increasing the expertise for SBC locally. Additionally, in Nicaragua UNICEF provided direct support training other partners in communication for development (C4D) methodology, so that the focus of the messaging was on increasing the audience's perception of Zika risk.

As a result of all these efforts and their involvement in the Zika response, IPs and ministries of health perceived an increased capacity to develop and implement effective SBC activities, which positively influences the likelihood of improvement in SBC programming. Specifically, partners discussed having developed skills to more effectively serve future SBC work in the region through IPC capacity-building provided by Breakthrough ACTION.

It is worth mentioning that USAID requested that [Breakthrough ACTION] provide a training and, I don't know if you know this, we began with provincial health offices, which are part of the strengthening strategy. However, the ministry saw how important and successful it was, that they requested that we complete the training with the other 24 provinces so the entire country could receive the part of behavioral change....

\subsection{Monitoring, evaluation, research, and learning}

The purpose of MERL activities is to apply knowledge gained from evidence and analysis to improve programmatic and health outcomes and ensure accountability for the resources used to achieve them. ${ }^{19}$ Within a public health emergency response, complexity is heightened by the time-scarce nature of the emergency and the number of potential settings and stakeholders engaged. This complexity requires special consideration to ensure that MERL objectives are aligned and harmonized across partners' responses. It is beneficial to develop an agreedupon MERL framework for SBC at the outset of a public health emergency response among IPs. This aids in the development of processes and methods to set priority SBC MERL objectives, harmonize measurement, align data collection, and develop research utilization plans for primary and secondary audiences.

\section{Recommendation 6}

Ensure that SBC activities are based on addressing contextually relevant determinants, facilitators, and barriers of behaviors that have been identified from rapid formative research conducted at the start of a response.

Formative research was recognized by all interviewed stakeholders as crucial for effective program design, as it allowed implementers to understand specific behavioral determinants, facilitators, and barriers that can be addressed through targeted, contextually appropriate SBC programming among identified primary and secondary audiences to achieve behavioral outcomes (see Box 5). A landscaping report conducted by $\mathrm{HC} 3$ and completed in June 2016 recommended that formative research be conducted in all countries to better understand barriers to uptake of prevention behaviors, as well as behavioral determinants that needed to be addressed in order to successfully implement SBC programming. ${ }^{20}$ The importance and role of formative research was also confirmed by IPs participating in a USAID Zika partners meeting sharing lessons learned among partners. ${ }^{9}$ Due to the perceived urgency to begin implementation of programs, many projects within the response did not carry out formative research in order to inform early program development, testing of prevention messages and materials, and development of SBC activities. Even when incorporated into project planning, formative research was often not conducted rapidly and was perceived to be carried out at a slower pace more common 


\section{BOX 5 WHAT IS FORMATIVE RESEARCH?}

Formative research allows program implementers to understand the health problem being addressed and answers questions such as "why" and "how" to define approaches and create tools and materials given the local context. Formative research also ensures that a program or program activity is feasible, appropriate, and acceptable in the context before it is fully implemented and can signal important constructs that should be included in implementation of monitoring systems. It is usually conducted when a new program or activity is being developed or when an existing one is being adapted or modified. ${ }^{21}$ Formative research may include:

- Published and programmatic document reviews and syntheses

- Secondary analysis of existing data sources, including survey and routine data (see Box 7)

- New quantitative and qualitative data collection and analysis

- Developing and validating detailed theories of changes

- HCD or participatory approaches

Annex 2 provides more information on different methodologies used for rapid formative research as well as methodologies appropriate for ongoing monitoring of SBC programs, with a summary of advantages and disadvantages for each one.

and appropriate in the context of a development project, and thus untimely for appropriate use in early program design.

[Implementing partners] need to have
rapid data collection methodologies
and not rely on the standard, classic develop-
ment methodologies involving longer-term
formative research...the lack of formative
research in most of the projects was a big
issue in terms of then how effective the
interventions could be....

-USAID, HQ

The consequences of not using timely formative assessments to guide SBC program design were exemplified by experiences in the response around the promotion of condom use for pregnant women for the prevention of Zika. For example, while preventing Zika during pregnancy is critical due to the potential health consequences for a developing fetus,${ }^{4}$ sociocultural and gender norms that affected uptake and practice of condom use were not initially accounted for in SBC programming. In the region, it is difficult for women to negotiate condom use with their male partners. Similarly, research conducted with Latino youth in the United States shows that women who intend to use condoms are less likely to do so in comparison with men who intend to use condoms, signaling more barriers to use for women. ${ }^{22}$ Condom use during pregnancy is even more difficult to adopt, as it is not considered a normative behavior during pregnancy. ${ }^{23,24}$ SBC and community engagement partners were slow at the start to recognize the limitations of their strategies to address these gender complexities and did not consider men as a potential target audience given their decision-making role.

During a focus group with men who were partnered with pregnant women, after we mentioned that often men would not join their wives for prenatal visits, one of the things they said was that they didn't see men included in the [SBC] campaigns. They said that all [SBC] messages were directed at women, and that they did not see men in these messages. This [observation] completely flipped our message around, and new content aimed specifically at men were created. Now [SBC material] included not only women, but also a couple. We realized that they were completely right, because we had been talking about condom use during pregnancy, but the decision on using condoms doesn't depend exclusively on the woman, but on the couple, including the man. So this helped us focus our communication strategy, understand[ing] that these key messages had to be aimed at different populations, including [the] male 


\section{population, specifically those partnered with these women.}

\section{-IP, El Salvador}

Year 2 of the Zika response saw an upsurge of formative research completed and shared to improve upon SBC program design, including appropriate channels and accompanying materials (see Box 6).

\section{BOX 6 EXAMPLE OF FORMATIVE RESEARCH}

Community engagement partners recognized that developing communication materials using participatory action research (PAR) is a best practice in the prevention and control of arboviruses and that it is essential for future emergency responses. ${ }^{10}$ Utilizing this practice allows for development of SBC communication materials that include local knowledge gathered from the people who live in the community, complementing scientific knowledge so that key messages can be adapted to address the main obstacles that people may face in a local context.

In one of the projects involved in the response, the plans for development of communication materials at the beginning of the response included results from PAR to complement the Zika Prevention Behavior Matrix. Focus groups (among pregnant women, women of childbearing age, and heads of families) as well as community health volunteers were used to validate the key messages included in the communication materials, ensuring that the language and photographs used for the promotion of SBC were relevant to the priority population.

It became obvious from practice and emerging research evidence throughout the epidemic that engaging both men and women in Zika virus prevention was essential. Projects worked to address this gap in their implementation phase and began to incorporate activities such as male-centered sensitization training, male-focused engagement activities, couples counseling, community forums, and targeted communication campaigns. Formative research earlier on in the process would have identified this issue as a potential barrier to this prevention behavior and ensured that activities to address gendered decision-making were originally included.

In future public health emergency responses, IPs should prioritize formative research at the beginning of a response despite the perceived urgency to rapidly implement. Co-designing and implementing joint formative research activities may be one way of balancing the need for rigorous yet rapid research for appropriate SBC design and programming in an emergency response. For example, different partners could lead inquiry with different key audiences, and joint analysis and interpretation of data may reduce the time taken to arrive at actionable insights. If this proven practice is not undertaken, IPs risk designing and implementing contextually and culturally inappropriate materials and activities, resulting in a waste of finite resources and time. This recommendation is supported by other documentation efforts carried out by Zika partners, who recommend performing rapid diagnoses to identify the perceptions of risk and other factors in the different socioecological levels (individual, interpersonal, organizational, and community), as well as determining knowledge, attitudes, and practices that exist in relation to the control and prevention of the disease outbreak. ${ }^{9}$ Box 7 presents an example of secondary analysis using KAP data to assess the effect of home visits on self-reported prevention behavior.

\section{Recommendation 7}

Agree upon indicator definitions and data sources among a specified list of SBC key indicators to allow for comparability across partners and countries; building in flexibility by using sub-indicators that are specific to IP programs or are needed for context-specific reasons.

During the Zika response, IPs needed data to inform the design of interventions, to establish benchmarks, and to monitor the process, outputs, and outcomes to carry out mid-course corrections. USAID needed monitoring data to report to their stakeholders. An agreed-upon MERL framework for such a response should be flexible enough to include data needs of different stakeholders but also ensure that a core set of key indicators be defined from the beginning and collected in a standardized way across the response to allow for comparability. Consistently collected data for a standardized set of key indicators would allow for better monitoring and comparison of SBC programming across the response for documentation and continuous improvement. One recommended 


\section{BOX 7 EXAMPLE OF A SECONDARY DATA ANALYSIS CONDUCTED WITH KAP DATA IN THE CONTEXT OF THE USAID ZIKA RESPONSE}

Home visits are extensively used as an SBC activity, most commonly as part of a package of activities. The effect of home visits by themselves on behavioral outcomes is rarely evaluated. However, some evidence exists that in a public health emergency context, home visits are independently effective in improving behavioral determinants and outcomes. ${ }^{25}$ Using multivariate probit regression models on a pooled four-country dataset, Breakthrough RESEARCH tested the relationship between home visits and three vector-control behavioral outcomes (scrubbing water containers, covering water containers, clearing stagnant water) to determine whether home visits that have an information-sharing component were associated with higher likelihood of doing preventative vector behaviors than those that only included direct vector-control action. We found that, relative to respondents who reported not being visited in their homes, respondents who received home visits that included both information-sharing (i.e., discussing information about mosquitoes and how they breed) and direct interventions such as application of larvicide or elimination of breeding sites were associated with higher likelihood of self-reported scrubbing of water containers (marginal effect $=41 \%, p<0.01$ ), controlling for country and ideational factors. This effect was not found for the other vector-control behaviors. Respondents who reported home visits that included only either information-sharing or direct action were not more likely to report performing any vector-control behavior.

approach is to use the "SMART" criteria when developing indicators (See Box 8).

SBC IPs relied mostly on KAP surveys to monitor knowledge about Zika and behavioral outcomes. In the USAID Zika response, these KAP instruments were not consistent across settings-in some cases, not even from one country to another within the same organization. This lack of consistency prevented data aggregation for many indicators as well as data comparison between IPs (see Box 9). However, it is recognized that there is tremendous value added among IPs having a sub-set of country- or contextually specific indicators that are linked with their specific activities, which may differ from other IPs based on initial formative research and other data used to design the program.
We have had some [challenges] that have to do with...having so many different projects and so many countries. Each country has begun their study at a different time, and surveys have varied accordingly, which has made comparison and measurement more difficult.

-USAID, Field

\section{BOX 8 “SMART” INDICATOR CHARACTERISTICS}

"SMART" indicators have the following characteristics:*

- Specific: The indicator should accurately describe what is intended to be measured and should not include multiple measurements in one indicator.

- Measurable: Regardless of who uses the indicator, consistent results should be obtained and tracked under the same conditions.

- Attainable: Collecting data for the indicator should be simple, straightforward, and cost-effective.

- Relevant: The indicator should be closely connected with each respective input, output, or outcome.

- Time-bound: The indicator should include a specific time frame.

\footnotetext{
*https://www.thecompassforsbc.org/how-to-guides/how-develop-indicators\#main-content
} 


\section{Recommendation 8}

Given the constraints of public health emergency responses, ensure coordination of research and evaluation activities from the beginning of the response.

There were several challenges associated with data collection and evidence generation during the response. As was described under Recommendation 6, not all IPs developed and implemented formative research, and even among those that did, the formative research was generally conducted relatively late in the response cycle. A second challenge experienced with MERL was a lack of consistency in questions used to monitor behavioral determinants and outcomes for SBC programming (see Recommendation 7). Third, stakeholders perceived that although there were many research studies carried out throughout the response, and all partners were reporting monitoring data to USAID, there was no clear mechanism to share data among partners to learn from the broader response.

Stakeholder interviews revealed that the most important lesson learned in the area of MERL was the need for greater coordination among partners for MERL-related activities. Interviewed stakeholders expressed that the response would have benefited from a designated technical partner to coordinate MERL activities for SBC programming throughout the response.

To facilitate implementation of the recommendations presented in this MERL section, a dedicated technical assistance partner could be included in the response. With increased IP-led coordination, conducting formative research that is scientifically sound and can be implemented rapidly could be shared among partners in the same geographic area within a country. Additionally, the dedicated IP could facilitate a participatory process for development of a MERL framework, including development of processes and methods to set priority MERL objectives, harmonize measurement, align data collection, and develop research utilization plans to ensure data is opportunely shared among partners to facilitate decision-making processes.
It would have been useful to include a partner that focused on designing a monitoring and evaluation model for the entire Zika response area dedicated to social and behavioral change, as it would have allowed us to shape the activities throughout the project... What do I mean by this? There could have been a framework for measuring and monitoring behavioral changes, with indicators that we all agree on, measured independently by a partner who specifically focuses on that task, as well as providing monitoring and decision-making information for all other partners, no?

-IP, Regional

\section{BOX 9}

Breakthrough RESEARCH assessed the comparability of 11 KAP data collection instruments across 10 SBC and community engagement IPs. Three main dimensions of information were compared: Knowledge (Zika awareness, Zika transmission, signs and symptoms, health risks and potential health outcomes, preventive behaviors); Attitudes (perceived risk of Zika, perceived efficacy of preventive behaviors, perceived self-efficacy); and Practices (preventive behaviors).

Knowledge questions and perceived risk were most comparable, requiring relatively simple data manipulation, such as combining categorical response options, for better comparability. However, questions measuring preventive practices were not at all comparable across surveys, as described below.

Several methodological issues impeded the comparability of indicators derived from KAP surveys:

- Questions used for indicators varied significantly in wording construction and timeframe.

- Sampling methodologies used to obtain the data ranged from mobile-phone-based sampling to multilevel cluster sampling, with inestimable differences in inherent biases.

- Sampling frames within each country differed, even among studies using probability sampling. 
The spread of Zika in Latin America in early 2015 caused grave concern and calls for quick action as microcephaly incidence increased and CZS and other neurological disorders were ultimately linked to Zika virus infection. Even though four years later Zika is no longer making headlines as a global health emergency, the virus continues to have the potential to rapidly spread if conditions are right. WHO has identified 61 countries at risk for Zika outbreaks due to the presence of the virus's carrier: the Aedes aegypti mosquito, including China, Egypt, and Pakistan, as well as many in Africa which are highly populated places ripe for quick transmission. ${ }^{26}$ In combatting these recurring threats as well as other emerging ones, the Zika experience offers several lessons. This document presented eight recommendations based on the lessons learned through the SBC programming of the USAID Zika Response. Incorporating these recommendations into future emergencies will help increase the likelihood of high-quality SBC programming, which is essential for better health outcomes.
While massive communication strategies have helped make Zika visible, we have seen that they have not been able to fully change behaviors. What we have identified is that we need our communication work to be more interpersonal. These are pretty much both phases of our work: first, positioning the Zika virus among the community, and then working on behavioral changes in reference to the behaviors prioritized by the project and suggested by USAID's behavioral matrix. This has been an instrument that has also helped us improve and refine our strategies.

$-I P$, Peru

[In documenting the lessons learned]

we will be able to more thoughtfully plan and roll out the SBC component in a future response.

-USAID, HQ

\section{TO LEARN MORE ABOUT SBC PROGRAMMING IN THE USAID ZIKA RESPONSE VISIT:}

(Titles below link to relevant web pages.)

- Zika Communication Network. This page is the main knowledge management platform for Zika-related tools and documentation. It brings together many resources from USAID IPs but is not exclusive to those working in this response.

- Promoting Social and Behavior Change During the USAID Zika Response. This page brings together many documents referenced in this document, such as the behavior prioritization technical guidance documents, a call to action for stakeholders to ensure behavior prioritization is included in future emergency responses, success stories, job aids, and tools.

- Prioritizing Behaviors and Strategies for Zika. This page brings together resources and examples of behavior prioritization experiences known to date. 


\section{Annex 1: Interviewee Representation}

\begin{tabular}{|c|c|c|c|c|c|c|c|c|}
\hline ORGANIZATION & $\begin{array}{c}\text { HQ / } \\
\text { REGIONAL }\end{array}$ & $\begin{array}{l}\text { DOMINICAN } \\
\text { REPUBLIC }\end{array}$ & $\begin{array}{c}\text { EL } \\
\text { SALVADOR }\end{array}$ & $\begin{array}{l}\text { LOCATION } \\
\text { GUATEMALA }\end{array}$ & HONDURAS & JAMAICA & PERU & $\begin{array}{l}\text { SUB- } \\
\text { TOTAL }\end{array}$ \\
\hline USAID & 3 & 1 & 1 & 1 & 1 & 1 & 1 & 9 \\
\hline $\begin{array}{l}J H \cup C C P \\
(H C 3 / B-A)\end{array}$ & 4 & 1 & 1 & 1 & 1 & - & - & 8 \\
\hline UNICEF & 2 & 1 & 1 & 2 & 1 & 1 & 1 & 9 \\
\hline PSI/PASMO & 3 & 1 & 2 & 2 & 2 & - & - & 10 \\
\hline MCDI & 1 & - & 2 & 2 & - & - & - & 5 \\
\hline Save the Children & 3 & 1 & 2 & - & 2 & - & - & 8 \\
\hline $\begin{array}{l}\text { Global } \\
\text { Communities }\end{array}$ & 2 & - & - & - & 2 & - & - & 4 \\
\hline CARE & 1 & - & - & - & - & - & 2 & 3 \\
\hline IFRC & 2 & - & - & - & - & 2 & - & 4 \\
\hline Abt Associates & 1 & 1 & - & 1 & 1 & 1 & & 5 \\
\hline $\begin{array}{l}\text { University Research } \\
\text { Co. (URC) }\end{array}$ & 2 & 1 & 1 & 1 & 2 & - & - & 7 \\
\hline $\begin{array}{l}\text { Pan American } \\
\text { Health Organiza- } \\
\text { tion (PAHO) }\end{array}$ & 1 & - & - & - & - & - & - & 1 \\
\hline Ministry of Health & - & 1 & 1 & 1 & 1 & - & - & 4 \\
\hline Sub-total & 25 & 8 & 11 & 11 & 13 & 5 & 4 & 77 \\
\hline
\end{tabular}




\section{Annex 2: Examples of Rapid Data Collection Techniques}

At the time of an outbreak or public health emergency, stakeholders require high-quality and reliable information to make decisions about how best to address the emergency. In these scenarios, IPs need to review existing data where available (IP reports, existing formative data, etc.). When the public health emergency involves a new disease, or a known disease emerging in new contexts, IPs need to collect valid data quickly and reliably in order to analyze, interpret, and apply to program planning and implementation as quickly as possible. During public health emergency responses there are different information needs. Understanding what questions need to be answered, at what point they need to be answered, and how they can best be answered in the quickest way possible is crucial. The table below proposes methodologies that can be streamlined, focused, and geared toward programmatic application. Note that requesting ethical approval before collecting data from communities is considered a best practice. 


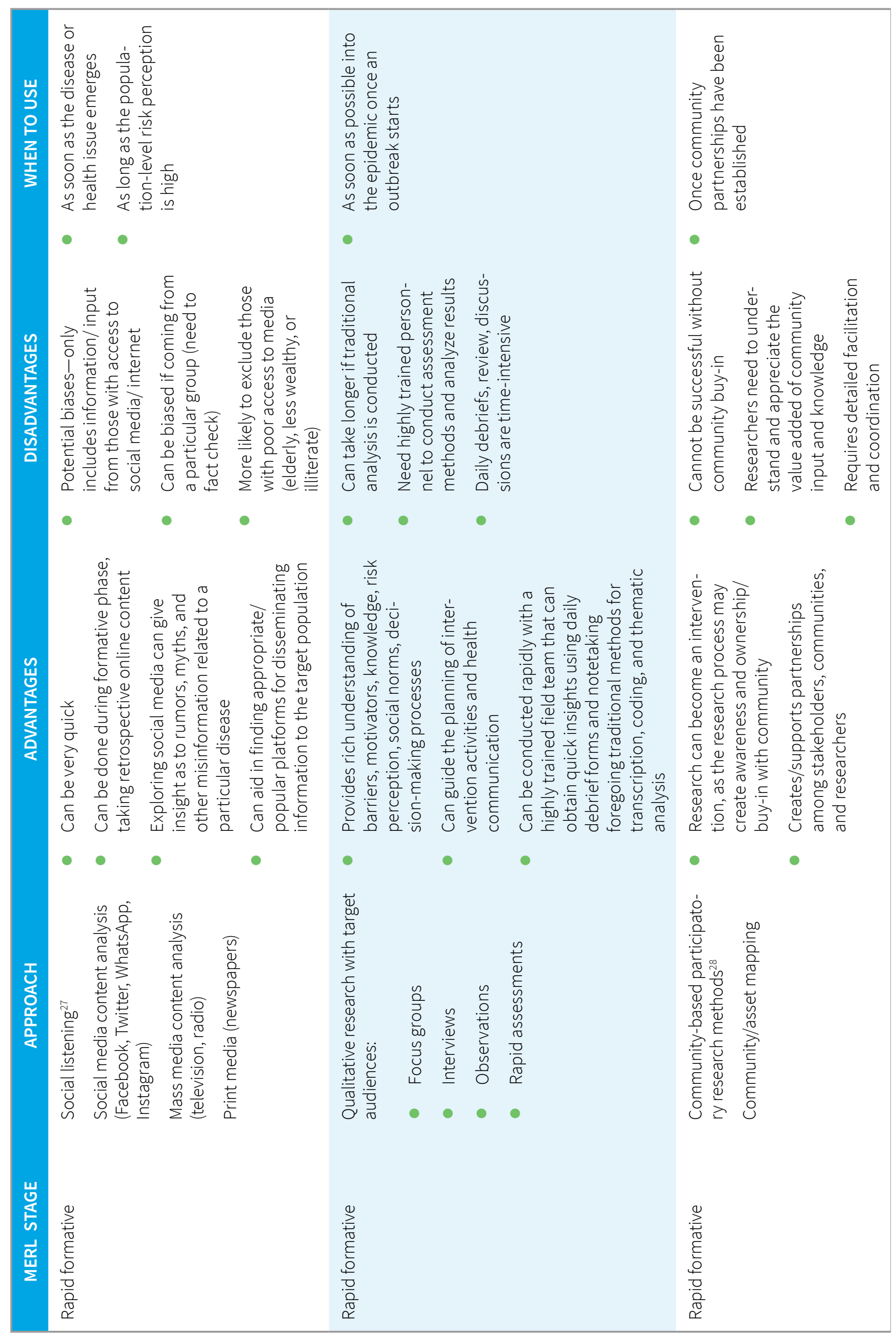




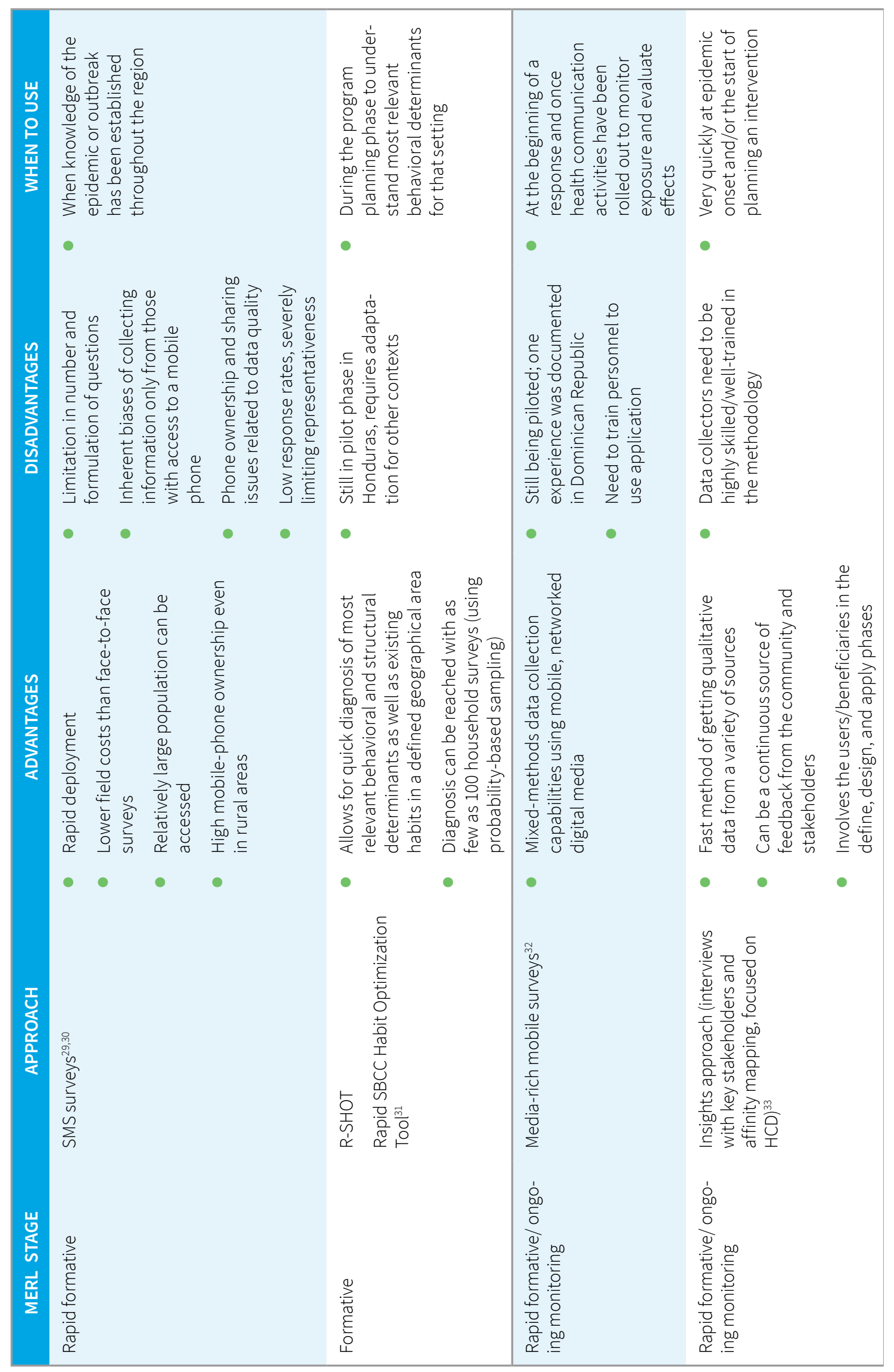




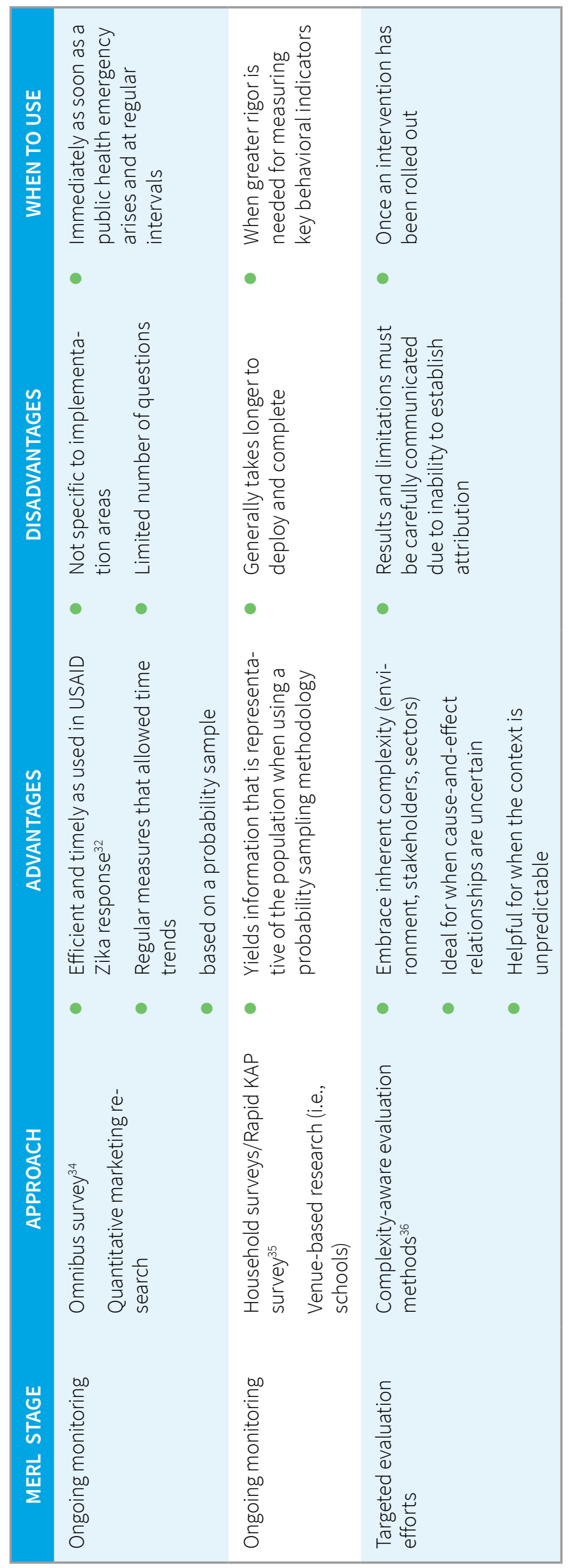




\section{References}

1. World Health Organization. 2016. "Fifth meeting of the Emergency Committee under the International Health Regulations (2005) regarding microcephaly, other neurological disorders and Zika virus." Geneva: WHO. https://www.who.int/en/news-room/ detail/18-11-2016-fifth-meeting-of-the-emergency-committee-under-the-international-health-regulations-(2005)-regarding-microcephaly-other-neurological-disorders-and-zika-virus. Accessed 5 June 2019.

2. Haby, M., M. Pinart, V. Elias, and L. Reveiz. 2018. "Prevalence of asymptomatic Zika virus infection: A systematic review," Bulletin of the World Health Organization 96(6): 402-413D. doi: 10.2471/ BLT.17.201541

3. World Health Organization. 2018. "Zika virus," Fact sheets Website. Geneva: WHO. https://www.who. int/en/news-room/fact-sheets/detail/zika-virus. Accessed 5 June 2019.

4. Centers for Disease Control and Prevention. 2019. "Congenital Zika syndrome \& other birth defects." Atlanta, GA: CDC. https://www.cdc.gov/pregnancy/ zika/testing-follow-up/zika-syndrome-birth-defects. html. Accessed 5 June 2019.

5. Doran, F. and S. Nancarrow. 2015. "Barriers and facilitators of access to first-trimester abortion services for women in the developed world: A systematic review," Journal of Family Planning and Reproductive Health Care 41: 170-180. doi: 10.1136/ jfprhc-2013-100862

6. Breakthrough ACTION+RESEARCH. n.d. Zika prevention behavior matrix. In: Zika Communication Network.

7. Breakthrough ACTION. 2018 (Updated). "Technical specifications content guide for behaviors with high potential to prevent Zika." Baltimore, MD: Breakthrough ACTION. https://www.zikacommunicationnetwork.org/node/20354. Accessed 4 October 2019.

8. Breakthrough ACTION. n.d. "Empowering communities to fight Zika: Capacity strengthening during the Zika outbreak response." https://www.zikacommunicationnetwork.org/node/20585
9. CARE International. 2019. "Movilización de la comunidad para la respuesta a emergencias y epidemias: Aprender de la lucha contra el Zika." Quito, Ecuador.

10. Medical Care Development International. "Essential elements for community-based arbovirus prevention and control: A systematization of experiences in five Central American countries." 10 September 2019.

11. Breakthrough ACTION. n.d. "Strengthening the USAID Zika response: experiences from the Zika Social and Behavior Change Working Group." Baltimore, MD: Breakthrough ACTION. https://www.zikacommunicationnetwork.org/sites/default/files/sites/ default/files/Breakthrough\%20ACTION\%20Zika\%20 Brief_SBC\%20Working\%20Group.pdf

12. Chin, A.C. et al. 2017. "Comparative efficacy of commercial mosquito coils against Aedes aegypti (Diptera: Culicidae) in Malaysia: a nationwide report," Journal of Economic Entomology 110(5): 2247-2251. doi: 10.1093/jee/tox183

13. Amelia-Yap, Z. H. et al. 2018. "Efficacy of mosquito coils: cross-resistance to pyrethroids in Aedes aegypti (Diptera: Culicidae) from Indonesia," Journal of Economic Entomology 111(6): 2854-2860. doi: 10.1093/jee/toy296

14. Bowman, L.R., S. Donegan, and P. J. McCall. 2016. "Is dengue vector control deficient in effectiveness or evidence?: Systematic review and meta-analysis," PLOS Neglected Tropical Diseases 10(3): e0004551. doi: 10.1371/journal.pntd.0004551

15. Pinchoff, J. et al. 2019. "Evidence-based process for prioritizing behavior-change messages: Zika prevention in Latin America and the Caribbean and applicability to future health emergency responses," Global Health: Science and Practice 7(3):404-417; https://doi.org/10.9745/GHSP-D-19-00188

16. Breakthrough ACTION. Reinventing water storage in Jamaica: A Human-Centered Design approach to Zika prevention. n.d.

17. SSI/Amos. Water barrel lid effectiveness trials. In: Presentation to the USAID Zika SBC Technical Working Group. 
18. ideo.org. n.d. "What is human-centered design?" DesignKit Web site. https://www.designkit.org/ human-centered-design. Accessed 11 December 2019.

19. Learning Lab. M\&E for learning. USAID. CLA toolkit Website. https://usaidlearninglab.org/qrg/me-learning. Published n.d. Accessed 5 June 2019.

20. Health Communication Capacity Collaboration. 2016. "HC3 landscaping summary report on Zika coordination and communication in four countries: Honduras, El Salvador, Dominican Republic and Guatemala March-April 2016." Baltimore, MD: Johns Hopkins Center for Communication Programs.

21. Centers for Disease Control and Prevention. n.d. "Types of evaluation." https://www.cdc.gov/std/ Program/pupestd/Types\%20of\%20Evaluation.pdf. Accessed 11 December 2019.

22. Tschann, J. M. et al. 2010. "Condom negotiation strategies and actual condom use among Latino youth," Journal of Adolescent Health 47(3): 254-262. doi: 10.1016/j.jadohealth.2010.01.018

23. Marteleto, L. J., A. Weitzman, R. Z. Coutinho, and S. Valongueiro Alves. 2017. "Women's reproductive intentions and behaviors during the Zika epidemic in Brazil," Population \& Development Review 43(2): 199-227. doi: 10.1111/padr.12074

24. Zorrilla, C. D., A. M. Mosquera, S. Rabionet, and J. Rivera-Viñas. 2016. "HIV and ZIKA in pregnancy: parallel stories and new challenges," Obstetrics \& Gynecology International Journal 5(6): 180. doi: 10.15406/ogij.2016.05.00180

25. Gamma, A. E., J. Slekiene, and H. J. Mosler. 2019. "The impact of various promotional activities on Ebola prevention behaviors and psychosocial factors predicting Ebola prevention behaviors in the Gambia evaluation of Ebola prevention promotions," International Journal of Environmental Research and Public Health 16(11): E2020. doi: 10.3390/ ijerph16112020.

26. World Health Organization. 2019. "Zika epidemiology update." https://www.who.int/emergencies/ diseases/zika/epidemiology-update/en/. Accessed 24 September 2019.

27. Murray, S. A. et al. 1994. "Listening To local voices: adapting rapid appraisal to assess health and social needs in general practice," British Medical Journal 308(6930): 698-700. doi: 10.1136/bmj.308.6930.698
28. Community Tool Box. Section 2. 2019. Communitybased participatory research. University of Kansas. Chapter 36 Web site. https://ctb.ku.edu/en/table-ofcontents/evaluate/evaluation/intervention-research/ main. Accessed 15 October 2019.

29. Berman, A., M. E. Figueroa, and J. D. Storey. 2017. "Use of SMS-based surveys in the rapid response to the Ebola outbreak in Liberia: opening community dialogue," Journal of Health Communication. 22(sup1): 15-23. doi: 10.1080/10810730.2016.1224279

30. Health Communication Capacity Collaborative. 2017. "Zika prevention knowledge and behaviors in Dominican Republic, El Salvador, Guatemala and Honduras." Baltimore, MD: Johns Hopkins Center for Communication Programs.

31. Storey, J. D. et al. 2019. "Study 2 report: Designing and testing of a rapid SBCC habit optimization tool in Honduras. Baltimore, MD: Johns Hopkins Center for Communication Programs.

32. United States Agency for International Development and Centers for Disease Control and Prevention. 2018. "Media-rich mobile surveys for evaluation of Zika prevention interventions (INNOV02)." In presentation of preliminary results: Georgia Tech.

33. Breakthrough ACTION. 2019. "Insights report: Using human-centered design to identify improved behavioral and structural solutions for Zika prevention (45/55 gallon water drums)." Baltimore, MD: Breakthrough ACTION. https://www.zikacommunicationnetwork.org/node/20464

34. Population Services International, Panamerican Social Marketing Organization. 2017. "LAC Zika omnibus survey second round: Consolidated regional results."

35. Jiang, H. et al. 2016. "Rapid assessment of knowledge, attitudes, practices, and risk perception related to the prevention and control of Ebola virus disease in three communities of Sierra Leone," Infectious Diseases of Poverty 5(1): 53. doi: 10.1186/ s40249-016-0142-9

36. United States Agency for International Development. 2018. Discussion Note: Complexity-aware monitoring. Washington, D.C.: Bureau for Policy, Planning Learning. https://usaidlearninglab.org/sites/default/ files/resource/files/cleared_dn_complexity-aware_ monitoring.pdf 


\section{Population Council}

4301 Connecticut Ave., NW | Suite 280

Washington, DC 20008

+12022379400

breakthroughactionandresearch.org 